\title{
Kinerja Pelayanan Kantor Pertanahan Kabupaten Banjar Dalam Pembuatan Sertifikat Tanah
}

\author{
Agus Sya'bani Arlan \\ Sekolah Tinggi Ilmu Administrasi Amuntai Indonesia \\ e-mail: agussyabaniarlan@gmail.com
}

\begin{abstract}
Abstrak
Penelitian ini bertujuan untuk mendeskripsikan kinerja pelayanan, menganalisa faktor-faktor penghambat pelayanan dan menginterpretasikan model-model kinerja pelayanan Kantor Pertanahan Kabupaten Banjar. Penelitian ini menggunakan metode penelitian kualitatif dengan pendekatan deskriptif. Unit analisis penelitian adalah Kantor Pertanahan Kabupaten Banjar, dengan teknik pengumpulan data secara observasi, wawancara, dan dokumentasi.

Hasil penelitian menunjukkan bahwa kinerja Kantor Pertanahan Kabupaten Banjar dalam meningkatkan pendaftaran hak atas tanah sesuai amanat UU Pokok Agraria Nomor 5 Tahun 1960 tentang Peraturan Dasar Pokok-Pokok Agraria dan PP RI Nomor 24 Tahun 1997 tentang Pendaftaran Tanah, adalah: (1) dalam melayani administrasi bidang pertanahan tidak berjalan baik, dan (2) kurang optimal dalam sosialisasi bidang pertanahan.

Atas dasar hasil penelitian, dalam rangka meningkatkan kinerja Kantor Pertanahan Kabupaten Banjar dan pendaftaran atas tanah, maka hendaknya Pemerintah melaksanakan sosialisasi atau penyuluhan kepada masyarakat lewat media cetak dan elektronik. Serta meningkatkan anggaran biaya penyelenggaraan pensertifikatan hak atas tanah secara massal tanpa biaya, dan pembenahan peraturan tentang hak atas tanah dengan pasal yang bersifat memaksa dengan sanksi tegas kepada pemilik tanah yang belum mendaftarkan hak atas tanah..
\end{abstract}

Keywords: Pelayanan publik, Kinerja, Pertananahan

This study aims to describe the performance of the services, analyze the factor restricting services and interpret the models performance Office land District Banjar. This research uses qualitative research methods with the descriptive approach. Research analysis unit is the Office of the District Land Commission Banjar, with data collection techniques are observation, interview, and documentation.

The results showed that the performance of the District Land Office Banjar in improving registration of land rights according to commendation Agrarian Staple ACT No. 5 of 1960 concerning the basic rules of agrarian issues and PP RI Number 24 in 1997 about the land registry, are: (1) in the field of land administration serve does no go well, and (2) less than optimal in the socialization of land areas.

On the basis of research results, in order to improve the performance of the District Lnd Office Banjar and registration of land, then the Government should implement the socialization or outreach to the public through print and electronic media. As well as increasing the budget costs of organizing land rights en masse at no cost, and revamping the regulations concerning land rights to article that is forced by the sanctions firmly to the landowners who have yet to register their land rights.

Kata Kunci : Public Service, Performance, Land Right 


\section{PENDAHULUAN}

Pemerintah menjaga standar pelayanan publik sebagai suatu komitmen penyelenggara pelayanan untuk menyediakan pelayanan dengan suatu kualitas tertentu yang ditentukan atas dasar perpaduan harapan masyarakat dan kemampuan penyelenggara pelayanan. Penetapan standar pelayanan dilakukan melalui proses identifikasi jenis pelayanan, identifikasi pelanggan, identifikasi harapan pelanggan, perumusan visi dan misi pelayanan, analis proses dan prosedur, sarana dan prasarana, waktu dan biaya pelayanan. Proses ini sebagai standar pelayanan yang harus ditetapkan, dan mengenai kelembagaan yang mampu mendukung terselenggaranya proses manajemen yang menghasilkan pelayanan sesuai dengan standar yang telah ditetapkan dan sejalan dengan Undang-Undang Republik Indonesia Nomor 25 Tahun 2009 Tentang Pelayanan Publik, menjelaskan bahwa: "Standar pelayanan adalah tolak ukur yang dipergunakan sebagai pedoman penyelenggaraan pelayanan dan acuan penilaian kualitas pelayanan sebagai kewajiban dan janji penyelenggara kepada masyarakat dalam rangka pelayanan yang berkualitas, cepat, mudah, terjangkau dan terukur".

Dalam Keputusan Menteri Pendayagunaan Aparatur Negara Nomor 63 Tahun 2003 tentang Pedoman Umum Penyelenggaraan Pelayanan Publik, setiap penyelenggaraan pelayanan publik harus memiliki standar pelayanan dan dipublikasikan sebagai jaminan adanya kepastian bagi penerima pelayanan. Standar pelayanan merupakan ukuran yang dibakukan dalam penyelenggaraan pelayanan publik yang wajib ditaati oleh pemberi dan atau penerima pelayanan. Pelayanan publik oleh aparatur pemerintah Badan Pertanahan Nasional kepada rakyat sebenarnya merupakan implikasi dari fungsi aparat sebagai pelayan rakyat. Karena itu, kedudukan aparatur Badan Pertanahan Nasional dalam pelayanan umum (public services) sangat strategis karena akan sangat menentukan sejauh mana pemerintah mampu memberikan pelayanan yang sebaik-baiknya bagi rakyat, sehingga akan menentukan sejauh mana Badan Pertanahan Nasional menjalankan perannya dengan baik sesuai dengan tujuan pendiriannya. Yakni meningkatkan kesejahteraan masyarakat, dan Badan Pertanahan Nasional haruslah dapat memenuhi kebutuhan masyarakat dalam hal kepengurusan sertifikat tanah.

Aparatur Pemerintah Badan Pertanahan Nasional seharusnya memiliki standar pelayanan yaitu kualitas (mutu) dan kuantitas (jumlah) serta keahlian yang bagus agar pekerjaan yang dihasilkan juga dapat berkualitas, dan pengetahuan pekerjaan, inisiatif dalam melakukan pekerjaan, kecekatan mental atau kemampuan pekerjaan, sikap dalam bekerja serta disiplin waktu terhadap waktu pembuatan sertifikat tanah.

Di wilayah Kabupaten Banjar masih banyak terdapat tanah pertanian dan masih banyak masyarakatnya yang menjadi petani, baik sebagai pemilik maupun sebagai petani penggarap. Keberhasilan pembangunan di segala bidang, dengan adanya kemudahan transportasi, bidang pendidikan, penyebabnya terjadi perubahan pola pikir kehidupan masyarakat setempat dan kebiasaan dalam tatacara memenuhi kebutuhan hidup sehari-hari yang berkaitan dengan tanah pertanian.

Di wilayah Banjar selama 5 (lima) tahun terakhir terdapat kecenderungan adanya peningkatan minat masyarakat atas kepemilikan tanah secara hukum, meskipun hanya sekedar segel atau berupa Surat Keterangan Keadaan Tanah (SKKT) yang ditandatangani oleh Kepala Desa/Lurah dan Camat saja. Kecenderungan ini dipicu oleh beberapa hal, antara lain oleh semakin tingginya kesadaran masyarakat arti pentingnya bukti otentik kepemilikan tanah, dan juga oleh semakin tingginya tingkat pendidikan masyarakat, serta adanya peran serta masyarakat yakni tokoh masyarakat atau tokoh sentral yang bisa mempengaruhi pengikutnya dalam peningkatan kesadaran atas kepemilikan tanah secara hukum. 


\section{METODE}

Penelitian yang digunakan dengan mengunakan pendekatan kualitatif, yang mencerminkan segi alamiah yang dipertentangkan dengan kuantum atau jumlah, dan atas dasar pertimbangan itulah maka penelitian kualitatif diartikan sebagai penelitian yang tidak mengadakan perhitungan.

Penelitian kualitatif menekankan pada suatu proses, artinya penelitian bermaksud untuk menemukan, memahami, dan menjelaskan fenomena yang terjadi. Pendekatan tersebut digunakan dengan pertimbangan-pertimbangan:

1. Penelitian kualitatif menyajikan bentuk holistik (menyeluruh) dalam menganalisis suatu fenomena

2. Penelitian jenis ini lebih peka menangkap informasi kualitatif deskriptif dengan secara relatif tetap berusaha mempertahankan keutuhan (wholeness) dari objek, artinya bahwa data yang dikumpulkan dalam rangka studi kasus dipelajari sebagai keseluruhan yang terintegrasi.

Kemudian jenis penelitian yang digunakan adalah policy research. Menurut Majchrzak (Sugiyono:2006) policy research adalah: "suatu proses penelitian yang dilakukan pada, atau analisis terhadap masalah-masalah sosial yang mendasar, sehingga temuannya dapat direkomendasikan kepada pembuat keputusan untuk bertindak secara praktis dalam menyelesaikan masalah". Sehubungan dengan jenis penelitian tersebut, peneliti berupaya menemukan fakta dan data yang terjadi, mengenai kinerja pelayanan Kantor Pertanahan Kabupaten Banjar dalam pembuatan sertifikat tanah kepada masyarakat.

\section{HASIL DAN PEMBAHASAN}

Berdasarkan penelitian Penulis atas kebijakan Kantor Pertanahan Kabupaten Banjar dalam rangka menyelesaikan pensertifikatan hak atas tanah di seluruh Kabupaten Banjar yang dibutuhkan waktu ratusan tahun atau beberapa generasi, untuk itu Kantor Pertanahan mengeluarkan beberapa kebijakan sekaligus melakukan terobosan-terobosan di bidang pertanahan agar hak atas tanah yang belum bersertifikat dapat diselesaikan dalam jangka waktu 20 (duapuluh) tahun, bahkan masih bisa dipercepat lagi dengan meningkatkan pelayanan kepada masyarakat. Oleh karena itu, dalam rangka percepatan pelaksanaan pendaftaran tanah, Kantor Pertanahan Kabupaten Banjar menempuh berbagai kebijakan pembangunan pertanahan sebagaimana yang telah diuraikan di atas yang salah satunya dengan meningkatkan program persertifikatan massal untuk masyarakat miskin khususnya pelaku usaha kecil (UKM) melalui program Pensertifikatan Swadaya Masyarakat (PSM).

Selain itu Kantor Pertanahan Kabupaten Banjar telah mengeluarkan beberapa terobosan-terobosan pelayanan sertifikat tanah dengan sistem jemput bola untuk menjangkau masyarakat diantaranya dengan fasilitas Layanan Rakyat untuk Sertifikat Tanah (Larasita) dan Pendaftaran Tanah Sistematis Lengkap (PTSL), komputerisasi Kantor Pertanahan, dan sosialisasi pendaftaran tanah.

\section{Kinerja Pelayanan Kantor Pertanahan Kabupaten Banjar}

Berdasarkan hasil data penelitian bahwa kinerja Kantor Pertanahan Kabupaten Banjar dalam meningkatkan pendaftaran hak atas tanah sebagaimana yang diamanatkan oleh UUPA dan PP RI Nomor 24 Tahun 1997 tentang Pendaftaran Tanah, maka Kantor Pertanahan Kabupaten Banjar sebagai garda terdepan dalam melayani masyarakat dalam melaksanakan pendaftaran hak atas tanah dan pemeliharaan daftar umum pendaftaran tanah. Pertama, dalam memberikan pelayanan administrasi bidang pertanahan yang mana fakta di lapangan menunjukkan tidak berjalan baik, karena kurangnya sosialisasi ke 
masyarakat. Kedua, dalam memberikan kegiatan penyuluhan tentang pertanahan masih belum optimal atau jarang sekali dan belum tuntas serta masih memiliki banyak masalah.

\section{Faktor Penghambat Pelayanan Pendaftaran Hak Atas Tanah di wilayah Kabupaten Banjar}

Berdasarkan hasil penelitian dapat diketahui adanya beberapa faktor penghambat pelayanan pendaftaran hak atas tanah di wilayah Kabupaten Banjar, yaitu: pertama, faktor masyarakat yang kurang akan kesadaran hukum untuk mendaftarkan tanahnya secara tertib dan teratur untuk terwujudnya kepastian hukum. Kedua, kurangnya penerangan atau penyuluhan Kantor Pertanahan kepada masyarakat yang berdampak pada rendahnya inisiatif masyarakat untuk mendaftarkan hak atas tanahnya. Ketiga, faktor biaya mahal (birokrasi) di mana pendaftaran hak atas tanah sebagai suatu proses pelayanan yang meliputi aktivitas lapangan, proses administrasi dan penerapan hukum, melibatkan peran aparat pelaksana dan pemohon hak, sangat menentukan tercapainya tujuan pendaftaran hak atas tanah. Keempat, faktor sarana atau fasilitas yakni kualitas sumber daya manusia yang masih kurang dan dana yang tersedia untuk pengadaan peralatan pengukuran yang tua dan kuno, yang banyak tidak mencukupi volume pekerjaan. Kelima, faktor penegakan hukum di mana banyaknya tanah yang belum bersertifikat maupun yang sudah bersertifikat bisa saja bermasalah dikarenakan kurang adanya jaminan hukum dari Pemerintah.

\section{Model-model Kinerja Pelayanan Kantor Pertanahan Kabupaten Banjar}

Model-model kinerja Kantor Pertanahan Kabupaten Banjar dalam meningkatkan pendaftaran hak atas tanah antara lain: (1) mengembangkan program komputerisasi, (2) program Layanan Rakyat untuk Sertifikasi Tanah (Larasita), dan Pendaftaran Tanah Sistematis Lengkap (PTSL), serta (3) penyuluhan hukum bidang pertanahan khususnya tentang pendaftaran hak atas tanah.

\section{KESIMPULAN}

Berdasarkan uraian yang peneliti kemukakan di atas, akhirnya penelitian ini sampai pada kesimpulan sebagai berikut:

1. Kinerja Kantor Pertanahan Kabupaten Banjar dalam upaya meningkatkan pendaftaran hak atas tanah sebagaimana yang diamanatkan oleh UUPA dan Peraturan Pemerintah RI Nomor 24 Tahun 1997 tentang Pendaftaran Tanah, maka kantor Pertanahan Kabupaten Banjar sebagai garda terdepan dalam melayani masyarakat dalam melakukan pendaftaran hak atas tanah dan pemeliharaan daftar umum pendaftaran tanah. Sedangkan upaya yang dilakukan untuk meningkatkan pendaftaran hak atas tanah yaitu: (1) Memberikan pelayanan secara optimal di bidang pertanahan kepada masyarakat guna mendorong dan membangkitkan minat masyarakat untuk mendaftarkan hak atas tanahnya; (2) Melakukan penyuluhan hukum di bidang pertanahan; dan (3) Untuk mempercepat pensertifikatan dikeluarkan kebijakan melalui Program Proyek Operasional Agraria (Prona), Proyek Opersional Daerah Agraria (Proda), Sertifikat Massal Swadaya (SMS) atau Pensertifikatan Swadaya Masyarakat (PSM), Program Pembaharuan Agraria Nasional (PPAN), dan Pendaftaran Tanah Sistematis Lengkap (PTSL).

2. Faktor yang dapat menghambat pelayanan pendaftaran hak atas tanah di Kabupaten Banjar disebabkan oleh beberapa hal, yaitu: (1) Faktor masyarakat, (2) Kurangnya proses sosialisasi dan penyuluhan hukum kepada masyarakat baik melalui media cetak maupun elektronik tentang manfaat pendaftaran hak atas tanah untuk memperoleh bukti kepemilikan hak berupa sertifikat; (3) Faktor birokrasi di mana dalam hal ini pendaftran hak atas tanah membutuhkan biaya yang sangat mahal, prosedur yang berbelit-belit dan merepotkan serta 
memakan waktu yang berbulan-bulan bahkan tahunan; (4) Faktor sarana dan prasarana, yakni kualitas sumber daya manusia masih rendah, sehingga kendala krusial yang dihadapi oleh Kantor Pertanahan Kabupaten Banjar pada saat ini adalah terbatasnya tenaga profesional yang memadai, terutama tenaga-tenaga petugas ukur dan juga terbatasnya dana anggaran yang tersedia untuk pengadaan peralatan pengukuran yang sudah tua dan ketinggalan zaman; dan (5) Faktor penegakan hukum, di mana kurang adanya jaminan hukum dari Pemerintah.

3. Model-model kinerja Kantor Pertanahan Kabupaten Banjar untuk mengatasi minimnya pendaftaran hak atas tanah di wilayahnya yaitu dalam memaksimalkan program persertifikatan massal sebagaimana telah diuraikan di atas dan selain itu juga melakukan beberapa terobosan-terobosan pelayanan sertifikat tanah dengan sistem jemput bola untuk menjangkau masyarakat di antaranya melalui komputerisasi Kantor Pertanahan, Layanan Rakyat untuk Sertifikat Tanah (Larasita) dan Pendaftaran Tanah Sistematis Lengkap (PTSL), serta melakukan penyuluhan hukum di bidang pertanahan khususnya mengenai pendaftaran hak atas tanah sebagai bentuk pengabdian kepada masyarakat.

\section{SARAN}

Dalam upaya meningkatkan kinerja Kantor Pertanahan Kabupaten Banjar dan pendaftaran atas tanah, Penulis memberikan saran sebagai berikut:

1. Pemerintah perlu melakukan penyuluhan dan sosialisasi kepada masyarakat baik melalui melalui media cetak maupun elektronik. Tentang pentingnya pendaftaran hak atas tanah untuk memperoleh bukti kepemilikan hak berupa sertifikat, sehingga masyarakat tidak menganggap bukti pembayaran pajak, seperti petuk, pipil, letter c, ketitir, girik, Ipeda atau Pajak Bumi dan Bangunan (PBB), sebagai alat bukti kepemilikan hak atas tanah, yang dapat memberi jaminan kepastian hukum bagi hak atas tanahnya.

2. Meningkatkan anggaran biaya peyelenggaraan pensertifikatan hak atas tanah secara massal tanpa biaya atau gratis khususnya kepada masyarakat yang kurang mampu dan melakukan pembenahan terhadap peraturan yang mengatur tentang pendaftaran hak atas tanah dengan mencantumkan pasal yang bersifat memaksa yang memberikan sanksi secara tegas kepada pemilik hak atas tanah yang tidak mendaftarkan hak atas tanahnya.

\section{DAFTAR PUSTAKA}

[1]. Anonim, Keputusan Menteri Negara PAN Nomor 81 Tahun 1993 tentang Pedoman Tata Laksana Pelayanan Umum

[2]. Anonim. Peraturan Pemerintah Republik Indonesia Nomor 24 Tahun 1997 tentang Pendaftaran Tanah

[3]. Anonim. Instruksi Menteri Negara Agraria/Kepala BPN Nomor 3 Tahun 1998 tentang Peningkatan Efisiensi dan Kualitas Pelayanan Masyarakat di Bidang Pertanahan

[4]. Anonim. Peraturan Menteri Negara Agraria/Kepala BPN Nomor 3 Tahun 1999 tentang Pelimpahan Kewenangan Pemberian dan Pembatalan Keputusan Hak Atas Tanah 
[5]. Dale, Timple, 2001. Seri Manajemen Sumber Daya Manusia, Kinerja/Performance, Jakarta: Eki Media

[6] Gaspersz, Vincent, 1997. Manajemen Kualitas Dalam Industrialisasi, Jakarta: Gramedia Pustaka Utama

[7]. Keban, Yeremias T., 2004. Enam Dimensi Strategis Administrasi Publik: Konsep, Teori dan Isu, Yogyakarta: Gava Media

[8]. Moeleong, Lexy J., 2005. Metode Penelitian Kualitatif, Bandung: Remaja Rosdakarya

[9]. Moenir. 1992. Manajemen Pelayanan Umum di Indonesia. Jakarta: Bumi Aksara

[10]. Ndraha, Taliziduhu, 2002. Pengantar Teori Pengembangan Sumber Daya Manusia, Jakarta: Rineka Cipta

[11]. Parlindungan, A.P, 1999. Pendaftaran Tanah di Indonesia (Berdasarkan PP. 24 Tahun 1997) Dilengkapi dengan Peraturan Jabatan Pejabat Pembuat Akta Tanah (PP. 37 Tahun 1998), Bandung: Mandar Maju

[12]. Ratminto, dan Winarsih, Atik Septi, 2007. Manajemen Pelayanan,Cetakan Ke-2. Yogyakarta: Pustaka Pelajar

[13]. Sugiyono, 2009. Metode Penelitian Pendidikan Pendekatan Kuantitatif, Kualitatif, dan $R \& D$, Bandung: Alfabeta 